\title{
SETOR DE SANEAMENTO BÁSICO: ASPECTOS JURÍDICO-ADMINISTRATIVOS E COMPETÊNCIAS REGULATÓRIAS
}

I. Introdução; II. Características do Serviço de Saneamento Básico; III. Regime Jurídico do Serviço de Saneamento Básico; IV. Prestação do Serviço de Saneamento Básico; V. Remuneração pela Prestação do Serviço de Saneamento Básico; VI. Ativos Utilizados na Prestação do Serviço; VII. Competência Legislativa no Setor de Saneamento Básico; VIII. Competência para Prestar, Regular e Outorgar Serviços de Saneamento Básico; IX. Utilização e Propriedade das Fontes dos Recursos Hídricos; X. Parcerias Público-privado no Setor de Saneamento Básico; XI. Conclusão. Bibliografia

\section{Introdução}

Atualmente, o Brasil vive uma profunda revolução no campo da regulação dos serviços públicos. Após uma considerável reformulação ocorrida na segunda metade da década de 90, que teve por objetivo desvencilhar o Estado dos ônus decorrentes de uma série de atividades, entre serviços públicos e atividades econômicas, mediante a privatização de diversas empresas estatais e outorgas de concessões e outras formas de parcerias com agentes privados, vivemos em uma época em que se busca, cada vez mais, corrigir falhas estruturais do modelo implementado no passado no campo dos serviços públicos, bem como encontrar novas formas para permitir o ingresso de capitais privados com a finalidade de permitir o atendimento à demanda social pelos serviços públicos.

Nesta toada, encontra-se o setor de saneamento básico, como o setor com o menor grau de abertura à iniciativa privada, com os maiores problemas no campo regulatório, dada a ausência de regras setoriais específicas, e com uma das maiores

* Advogado em São Paulo. 
necessidades de novos investimentos para atendimento às necessidades de expansão e universalização dos serviços, bem como de manutenção das reservas de água necessárias à constante e adequada prestação dos serviços à coletividade.

Com vistas aos fatos brevemente expostos, o escopo deste artigo é descrever os principais aspectos jurídico-administrativos concernentes ao serviço de saneamento básico no Brasil, de acordo com a ordem constitucional vigente, bem como a análise de possíveis soluções que tenham por objetivo viabilizar o ingresso de recursos privados no sobredito setor, em união a esforços públicos (de ordem regulamentar e até mesmo fomentadora), de forma a possibilitar ao Poder Público o atendimento às necessidades da população.

\section{Características do Serviço de Saneamento Básico}

Primeiramente, deve-se ter claro que o serviço de saneamento básico no Brasil (assim como em grande parte dos países do mundo) é, tanto por conta de expressa previsão legal, quanto em razão de suas características intrínsecas, diretamente relacionadas com o interesse da coletividade, considerado serviço público. ${ }^{\prime}$ Desta forma, verifica-se a incidência de determinadas regras inerentes às atividades caracterizadas como serviços públicos, conforme será descrito a seguir.

O serviço de saneamento básico compreende as atividades de produção, adução e distribuição de água, bem como coleta, tratamento e disposição final dos esgotos, de forma que sua prestação implica a instalação de uma rede de provimento de serviços que transportará a água a ser fornecida aos consumidores finais bem como o esgoto produzido para tratamento em estações próprias.

Tendo em vista a existência da malha dutoviária, verifica-se a existência de monopólio natural na prestação dos serviços de saneamento básico, visto que a duplicação dos meios necessários para a prestação de tais serviços seria por demais custosa, ou mesmo inviável em determinadas situações ${ }^{2}$. Portanto, estes serviços são prestados normalmente por um único agente por região geográfica, de acordo com os critérios e requisitos descritos abaixo.

Dada a estrutura da prestação dos serviços de saneamento básico, a qual, frise-se, depende de rede de difícil ou até mesmo impossível duplicação, tem-se uma situação

1 Celso Antônio Bandeira de Mello define serviço público como: "serviço público é toda atividade de oferecimento de utilidade ou comodidade material fruivel diretamente pelos administrados, prestado pelo Estado ou por quem lhe faça as vezes, sob regime de Direito Público - portanto, consagrador de supremacias e de restrições especiais - instituído pelo Estado em favor de interesses que houver definido como próprios no sistema normativo" - in Curso de Direito Administrativo. 13a edição - 2001. Ed. Malheiros. São Paulo, p. 597.

2 Em excelente entendimento sobre a matéria, Alexandre Santos de Aragão afirma que: "O que ocorre, é que na maioria das vezes a duplicação das infra-estruturas é, senāo impossível, pelo menos irracional do ponto de vista econômico elou urbanístico, caracterizando-se a sua gestão como monopólio natural." In Serviços Públicos e Concorrência. "Revista de Direito Administrativo", 233/337. 
na qual até mesmo em países com alto índice de competição na prestação de serviços públicos, como o Reino Unido, por exemplo, a prestação dos serviços de saneamento básico é realizada de forma monopolística por um único agente por região ${ }^{3}$.

Destarte, o escopo deste artigo limitar-se-á a analisar as questões jurídico-administrativas mais relevantes admitindo-se apenas um prestador de serviços por determinada região, a variar conforme os centros competentes previstos na Constituição Federal (a serem descritos abaixo), sem considerar, portanto, a possibilidade de competição no setor de saneamento básico.

\section{Regime Jurídico do Serviço de Saneamento Básico}

Uma vez caracterizado o serviço de saneamento básico como serviço público, verifica-se a incidência de um regime de Direito Público sobre a prestação deste serviço, segundo o qual sua prestação não é livremente acessível a todos e quaisquer interessados, mas apenas ao Estado ou àqueles determinados pelo Poder Público de acordo com os critérios constitucionais e legais aplicáveis.

Após análise dos dispositivos constitucionais atinentes aos serviços públicos e atividades econômicas, temos clara a distinção entre três institutos distintos, quais sejam: (i) as atividades econômicas stricto sensu, que são aquelas atividades livremente acessíveis a quaisquer interessados que atendam aos requisitos legais aplicáveis, ex vi parágrafo único do artigo 170 da Constituição Federal; (ii) serviços públicos, que são aquelas atividades econômicas lato sensu titularizadas pelo Estado em decorrência de seu intenso interesse público, podendo ser exploradas por particulares mediante delegação do Poder Público ${ }^{4}$; e (iii) serviços públicos atividades administrativas, que são aquelas atividades típicas e exclusivas do Poder Público, impassíveis de delegação, que expressam o poder do Estado agindo nesta qualidade (poder de polícia) ${ }^{5}$.

À luz da descrição do serviço público de saneamento básico apresentada no item II acima, entendemos ser o serviço de saneamento básico uma atividade econômica lato sensu titularizada pelo Estado com o escopo de promover o bem-estar social e o desenvolvimento nacional ${ }^{6}$. Desta forma, tal caracterização implica a

3 Ao analisar os serviços de saneamento básico no Reino Unido, Simon Cowan afirma que "The water industry is the most monopolistic of the utilities that have been privatized in the United Kingdom. Duplication of the networks of water mains and sewerage is generally undesirable and there is, at present, no competition in supply using common networks. "In Competition in Regulated Industries, $1^{2}$ ed. - 1998. Oxford University Press. Oxford, p. 161.

4 Cf. ARAGÃO, Alexandre Santos de. Agências Reguladoras e a Evolução do Direito Administrativo Econômico. $1^{\mathrm{a}}$ ed. - 2002. Ed. Forense. Rio de Janeiro, p. 151.

5 Sobre tal distinção entre serviços públicos atividades econômicas e serviços públicos atividades administrativas: TÁCITO, Caio. A Configuração Jurídica do Serviço Público. "Revista de Direito Administrativo", 233/373-376.

6 É interessante mencionar que a configuração dos serviços públicos de saneamento básico como atividade econômica titularizada pelo Poder Público é igualmente adotada em Portugal, onde o 
obrigatoriedade de estrita observância dos termos do artigo 175 da Constituição Federal de 1988, o qual dispõe (in verbis):

“Art. 175. Incumbe ao Poder Público, na forma da lei, diretamente ou sob regime de concessão ou permissão, sempre através de licitação, a prestação de serviços públicos.

Parágrafo único. A lei disporá sobre:

I - o regime das empresas concessionárias e permissionárias de serviços públicos, o caráter especial de seu contrato e de sua prorrogação, bem como as condições de caducidade, fiscalização e rescisão da concessão ou permissão;

II - os direitos dos usuários;

III - política tarifária;

IV - a obrigação de manter serviço adequado."

Diante do artigo supramencionado, entende-se que as atividades caracterizadas como serviços públicos são incumbências essenciais do Poder Público, que é obrigado a sempre manter tais serviços disponíveis para a coletividade com vistas a assegurar o bem-estar social e a dignidade da pessoa humana. Com a finalidade de atingir os objetivos precípuos da titularização de determinada atividade econômica lato sensu (promover o bem-estar social, assegurar a dignidade da pessoa humana, etc.), o Poder Público pode delegar a particulares a exploração de atividades consideradas serviços públicos na forma prevista no artigo 175 da Constituição Federal, conforme será descrito abaixo.

Independentemente de haver prestação direta pelo Poder Público ou delegada a particulares, os serviços públicos, em virtude de sua extrema relevância para o interesse público, devem sempre obedecer a determinados princípios, dentre os quais mencionamos: (i) o Princípio da Universalidade, constante da obrigação de extensão da prestação do serviço ao maior número de usuários possível; (ii) o Princípio da Continuidade, constante da obrigação da prestação do serviço de forma contínua e adequada; e (iii) o Princípio da Modicidade Tarifária, constante da obrigação de cobrar-se os menores valores possíveis pela prestação dos serviços.

Conclui-se, portanto, que o serviço de saneamento básico, independentemente de ser prestado diretamente pelo Poder Público ou mediante delegação a particulares, deverá sempre ser prestado de forma contínua e com qualidade para o maior número de usuários possível e com remuneração tão módica quanto possível.

Poder Público é obrigado a prestar os serviços de saneamento básico e os particulares somente podem assumir tal atividade mediante concessão outorgada pelo Poder Público. Ao comentar o regime jurídico das atividades de saneamento básico, Diogo Freitas do Amaral afirma que "a titularidade e o exercício das actividades em causa são, por lei, reservados à Administração, podendo, no entanto, o exercício de qualquer uma delas - ou ambas simultaneamente - ser transferido para privados por concessão," In Estudos sobre Concessões e Outros Actos da Administração. $1^{\mathbf{a}}$ ed. - 2002. Ed. Almedina. Coimbra, p. 404. 


\section{Prestação do Serviço de Saneamento Básico}

Conforme já aludido, a prestação do serviço de saneamento básico é uma atividade de titularidade primeira do Poder Público, que tem a faculdade, no entanto, de delegá-la a um particular mediante concessão ou permissão, sempre precedida de licitação prévia ex vi artigo 175 da Constituição Federal, em sede de conveniência e oportunidade, obedecidos os requisitos constitucionais e legais. Verifica-se, assim, a existência de duas formas de prestação deste serviço, distintas no que tange ao ente prestador, quais sejam:

- Prestação Direta pelo Poder Público: o serviço é prestado diretamente pelo Poder Público, geralmente por meio de um órgão da administração indireta, em um processo de descentralização administrativa ou convênio, podendo, ou não, haver a participação de entes privados na consecução das obrigações públicas, sem, contudo, haver a transferência da atividade; e

- Prestação Mediante Delegação: o Poder Público outorga a uma pessoa jurídica de direito privado, com controle público ou privado, obrigatoriamente após uma licitação, a obrigatoriedade de prestar, por sua conta e risco determinado serviço público, sujeitando-se a um regime de direito público, de acordo com padrões de qualidade fixados pelo Poder Público e sob a sua constante fiscalização.

\section{(a) Prestação do Serviço de Saneamento diretamente pelo Estado}

Conforme aludido, o serviço de saneamento básico poderá ser prestado diretamente pelo Poder Público ou por terceiro, cujo controle poderá ser público ou privado. Quando prestado diretamente pelo Poder Público, verifica-se a existência de duas formas de prestação do serviço de saneamento básico: a descentralização administrativa e o convênio ou consórcio?

\section{(i) Descentralização Administrativa}

A descentralização administrativa, uma das formas de prestação direta pelo Estado, é a organização promovida interna corporis da Administração Pública para a prestação de serviço público ${ }^{8}$, mediante autorização legislativa. Ou seja, a Administração cria um ente dotado de personalidade jurídica própria, integrante da admi-

7 Convênio e consórcio são institutos previstos no artigo 241 da Constituição Federal, sendo o convênio formado por entes federativos de diferentes categorias (Estado e Município, por exemplo) e o consórcio formado por entes federativos da mesma categoria (diversos municípios, por exemplo). Cf. DI PIETRO, Maria Sylvia Zanella. Parcerias na Administração Pública. $4^{\mathrm{a}}$ ed. - 2002. Ed. Atlas. São Paulo, p. 189 e ss.

8 Celso Antônio Bandeira de Mello ensina que "a descentralização administrativa ocorre quando atividade meramente administrativa (não política, portanto), ou o exercício dela, se desloca do corpo orgânico da Administraçāo para uma outra pessoa." In Prestação de Serviços Públicos e Administração Indireta. $2^{a}$ ed. - 1983. Ed. Revista dos Tribunais. São Paulo, p. 8. 
nistração indireta (i.e., uma autarquia, empresa pública ou sociedade de economia mista), e dota referida entidade de competência para a prestação dos serviços.

Para que haja a caracterização da descentralização, é necessário que: (i) o ente prestador possua personalidade jurídica própria, autonomia patrimonial e competência específica para a titularidade e prestação ou, ao menos, prestação do serviço; (ii) a criação do ente prestador dos serviços seja feita por meio de lei, a qual fixará as competências e áreas de atuação da entidade constituída para a prestação dos serviços de saneamento básico, conforme inciso XIX do artigo 37 da Constituição Federal ${ }^{9}$; (iii) a outorga da competência da titularidade e prestação ou, ao menos, prestação do serviço decorra de lei; e (iv) haja transferência da titularidade e da prestação ou, ao menos, da prestação do serviço de saneamento básico, havendo, contudo. o controle por parte da Administração direta e demais mecanismos de controle constitucionalmente previstos ${ }^{10}$.

No caso do processo de descentralização envolver a criação de uma autarquia, haverá a transferência da titularidade e do exercício do serviço à autarquia, ao passo que se referido processo envolver a criação de uma empresa estatal, haverá apenas a transferência do exercício do serviço à empresa estatal.

Atualmente, há no Brasil diversas discussões doutrinárias acerca da natureza jurídica da relação existente nos casos em que a prestação de serviços públicos é desenvolvida por empresas públicas e sociedades de economia mista. Vale dizer, muito se questiona acerca da existência de prestação direta pelo Estado, em um processo de descentralização administrativa, ou da existência de delegação de serviços públicos (concessão ou permissão). Passaremos neste ponto a analisar com maior profundidade esta questão.

É possível afirmar-se que qualquer análise acerca desta matéria dependerá basicamente de dois fatores, quais sejam, a competência para a prestação do serviço em questão e o ente controlador da empresa pública ou sociedade de economia mista prestadora do serviço em questão.

Sendo assim, podemos afirmar que não haverá concessão quando um ente com a competência para prestar um determinado serviço público constituir uma empresa estatal ou uma autarquia para a prestação de tal serviço público, uma vez que neste caso haverá mera descentralização administrativa, posto que o ente federativo em questão apenas constitui um veículo apto a desenvolver uma obrigação que lhe é afeta.

9 Dispōe o inciso XIX do artigo 37 da Constituição Federal (in verbis): "somente por lei especifica poderá ser criada autarquia e autorizada a instituição de empresa pública, sociedade de economia mista e de fundação, (...)"

$10 \mathrm{O}$ controle aqui mencionado refere-se ao controle exercido pelo Ministério (no âmbito federal) ou pela Secretaria (nos âmbitos estadual e municipal) ao qual a respectiva entidade se vincula, mediante a indicação de seus dirigentes e administradores (os quais são exoneráveis ad nutum) e mediante o recebimento de balanços e demonstrativos que comprovem as condições financeiras da respectiva entidade, havendo o poder da Administração direta de intervir mediante a verificação de irregularidades (artigo 26, do Decreto-lei 200/67, como referência à legislação federal), bem como ao controle exercido pelo Poder Legislativo com o auxílio do Tribunal de Contas competente. 
A delegação de serviços públicos, como melhor se verá abaixo, é formalizada por meio de um contrato (de concessão ou de permissão, conforme o caso), que pressupõe a contraposição de interesses entre as partes, uma vez que o concessionário visa a prestação dos serviços com os menores gastos possíveis tendo em contrapartida a maior remuneração possível, ao passo que o concedente visa a prestação dos serviços mais ampla possível (com os maiores gastos possíveis por parte do concessionário) tendo em contraprestação as menores tarifas possíveis (em atendimento ao princípio da modicidade tarifária). Desta forma, ao verificar-se que concedente e concessionário encontram-se na mesma esfera administrativa (sujeitos, portanto, a uma única autoridade decisória), entendemos ser impossível a consideração da existência de delegação de serviços públicos, mas apenas de mera descentralização administrativa.

Para esclarecer esta hipótese podemos mencionar, exempli grafia, a criação, por um determinado município, de uma empresa estatal ou uma autarquia para a prestação de serviços de saneamento básico. Neste caso, a competência para a prestação do serviço é do município (inciso V, do artigo 30, da Constituição Federal), que apenas constitui um instrumento para viabilizar a prestação do serviço, configurando a prestação direta pelo Poder Público, não havendo, portanto, uma concessão de serviço público.

A contrário senso, haverá concessão de serviços públicos quando o ente que detiver a competência para prestar um serviço for distinto do ente que controlar a empresa estatal prestadora do serviço. Isto ocorre em razão de não se poder falar em descentralização administrativa, uma vez que o ente federativo criador do agente prestador dos serviços não é o mesmo do ente competente para a prestação dos serviços. A obrigação de prestação dos serviços é transferida para entidade sem qualquer relação (salvo pela concessão ou pelo convênio) com o ente federativo competente para prestar os serviços.

Para esclarecer a situação em questão, pode-se mencionar, exempli grafia, a prestação de serviços de saneamento básico por uma companhia estadual em um município que não integra uma região metropolitana. Neste caso, o município em questão é competente para prestar os serviços, mas, em razão de conveniência e oportunidade, transfere, por meio de convênio administrativo ou concessão (esta, precedida de licitação), a obrigação de prestar o serviço a uma empresa controlada pelo Estado, que não está, de qualquer forma, vinculada ao Município (exceto pelo convênio ou pela concessão).

Finalmente, vale apenas mencionar que Marçal Justen Filho" ${ }^{1}$ considera que jamais poderá haver relação de concessão quando o prestador do serviço for uma empresa estatal, uma vez que será o próprio Poder Público que prestará o serviço. Permissa maxima venia, entendemos, em virtude das considerações acima, que haverá concessão sempre que o prestador dos serviços não for controlado pelo ente

11 JUSTEN FILhO, Marçal. Teoria Geral da Concessão de Serviços Públicos. $1^{\mathrm{a}}$ ed. - 2003. Ed. Dialética. São Paulo, p. 117. 
competente para a prestação de tais serviços, consoante entendimento de Celso Antônio Bandeira de Mello ${ }^{12}$.

\section{(ii) Convênio Administrativo}

Segundo Caio Tácito, os convênios "são expressões modernas do federalismo cooperativo" 13 . O convênio administrativo ocorre quando a prestação de determinado serviço público de competência de um ente federativo é realizada por outro ente federativo ou entidade integrante de sua administração indireta ${ }^{14}$.

Valendo-nos do exemplo acima mencionado ao analisar a questão da existência ou não concessão, pode-se, exempli gratia, afirmar que o convênio se dá quando compete ao Município prestar o serviço de saneamento básico, mas este é efetivamente prestado por entidade estadual, sem que haja a edição de qualquer lei complementar estadual instituindo a criação de uma região metropolitana ${ }^{15}$.

O convênio administrativo é, assim, caracterizado pela conjugação de esforços de entes federativos distintos, mediante prévia autorização legislativa, com vistas à consecução de um serviço público cuja incumbência é de apenas um desses entes, havendo a transferência da execução do serviço público em questão e não da competência para prestá-lo.

Importante ressaltar que no convênio não há qualquer relação jurídica de natureza contratual entre o agente prestador do serviço e o titular da competência para prestá-lo, inexistindo, portanto, as garantias e prerrogativas inerentes ao regime de concessão.

Desta forma, tem-se que a diferença fundamental entre o convênio e a concessão consiste exatamente do fato de que a concessão envolve um conflito de interesses entre o Poder concedente e o concessionário, uma vez que a satisfação de um advém exclusivamente do cumprimento das obrigações pelo outro (conforme expusemos no subitem anterior). A contrário senso, o convênio tem como característica essencial a confluência de interesses, que não são contrapostos, mas sim, complementares, uma vez que a satisfação de ambas as partes advém da própria prestação do serviços, que será remunerada por tarifa, fixada, em regra, pelo agente prestador dos serviços ${ }^{16}$

12 Cf. Curso op. cit. Página 160.

13 TÁCITO. Caio. Temas de Direito Público (Estudos e Pareceres). $1^{\text {a }}$ ed. -2002 . Ed. Renovar. Rio de Janeiro. Página 114.

14 Os convênios administrativos, conforme já mencionado, são previstos no artigo 241 da Constituição Federal, que dispõe (in verbis): “A União, os Estados, o Distrito Federal e os Municípios disciplinarão por meio de lei os consórcios públicos e convênios de cooperação entre os entes federados, autorizando a gestão associada de serviços públicos, bem como a transferência total ou parcial de encargos, serviços, pessoal e bens essenciais à continuidade dos serviços transferidos." (Grifos Nossos)

15 Nos termos do parágrafo $3^{\circ}$, do artigo 25, da Constituição Federal, os Estados podem, mediante lei complementar estadual, instituir regiões metropolitanas visando integrar o planejamento, organização e a execução de funções públicas de interesse comum.

16 Cf. DI PIETRO, Maria Sylvia Zanella. Parcerias op. cit., p. 194. 
Conforme aludido, o serviço de saneamento poderá ser prestado diretamente pelo Estado ou por terceiro, cujo controle poderá ser público ou privado. Quando por terceiro, verifica-se a existência de duas formas de outorga do serviço de saneamento básico: a permissão e a concessão.

Assim sendo, verifica-se que não obstante o regime jurídico de outorga do serviço de saneamento básico a particulares seja na prática, preponderantemente, o regime de concessão, poderá haver a outorga por outro regime. Neste sentido, o art. 12 da Lei Estadual $n^{\circ} 7.750 / 92^{17}$ do estado de São Paulo determina que a outorga poderá ser feita pelos municípios em regime de concessão ou permissão.

Tendo em vista a possibilidade de outorga em pluralidade de regimes, cabe neste momento uma breve diferenciação dos institutos da concessão e da permissão, de acordo com excelentes definições de ilustres doutrinadores pátrios:

- Concessão: outorga, precedida de licitação, a terceiro, por meio de contrato com prazo de duração preestabelecido para a prestação de determinado serviço público em regime de direito público, por conta e risco do concessionário, de forma contínua e de acordo com padrões de qualidade preestabelecidos pelo poder concedente, sendo assegurado ao concessionário o equilibrio econômico-financeiro da relação jurídica constituída com o poder concedente, havendo a possibilidade de rescisão unilateral pela Administração mediante indenização ao prestador do serviço, nos termos dos artigos 35 et. seq. da Lei 8.987/95; e

- Permissão: outorga de permissão pelo Estado, precedida de licitação, por meio de contrato, para que o terceiro preste, em caráter precário, determinado serviço público, em regime de direito público, sendo a precariedade caracterizada pela possibilidade de rescisão unilateral pelo Poder Público e pela ausência de prazo de duração da permissão preestabelecido.

A concessão tem como característica essencial a garantia contratual que lhe é inerente de retomo e recuperação de investimentos, sendo condição fundamental para a realização de investimentos em indústrias intensivas de capital, como é o caso do saneamento básico.

Vislumbra-se, assim, que o regime de permissão não é adequado para o serviço de saneamento básico, posto que é necessária a garantia de retomo dos investimentos efetuados mediante mecanismos que assegurem os direitos do prestador dos serviços, especialmente em caso de término da outorga, sendo referidos mecanismos típicos da concessão. Ademais, considerando-se que a permissão não é tradicionalmente utilizada na outorga dos serviços de saneamento básico no Brasil, as considerações a seguir serão feitas tão-somente com relação ao regime de concessão ${ }^{18}$.

$17 \mathrm{O}$ inciso I, do artigo 12, de referida lei dispōe in verbis: "1. os serviços públicos de saneamento de âmbito municipal serão prestados pelo Poder Público Municipal, diretamente ou sob regime de concessão ou permissão;"

18 Cf. DI PIETRO, Maria Sylvia. Parcerias, op. cit., p. 130. 
A prestação do serviço de saneamento básico em regime de concessão possui as seguintes características: (i) será sempre precedida de licitação, sendo comumente adotadas as modalidades de concorrência ou leilão ${ }^{19}$; (ii) a outorga é formalizada por meio de contrato de concessão, o qual estabelece o prazo de duração da concessão, a área da concessão, os parâmetros de qualidade dos serviços, o regime de disponibilidade dos ativos e as fórmulas e indicativos utilizados para o reajuste e a revisão da remuneração; (iii) é remunerada por tarifa, a qual poderá ser oferecida em garantia de financiamentos contratados para viabilizar a implementação do serviço concedido ${ }^{20}$; (iv) acarreta ao concessionário responsabilidade civil objetiva, visto que a atividade é desenvolvida em regime de direito público, por força do disposto no $\S 6^{\circ}$, do artigo 37, da Constituição Federal; (v) garante ao concessionário o equilíbrio econômico-financeiro do contrato, mediante obrigação do Poder concedente de rever e reajustar periodicamente o valor da tarifa; e (vi) garante ao concessionário o direito à prévia e justa indenização na hipótese de extinção da concessão unilateralmente pelo Poder concedente.

Finalmente, vale ressaltar que, nos termos do artigo $2^{\circ}$, da Lei 9.074 , de 7 de julho de 1995, que estabelece as normas para outorgas de concessões e permissões de serviços públicos, não é necessária a edição de lei autorizativa para a outorga de concessão de serviços de saneamento básico. Em que pese o regime estabelecido para o setor de saneamento básico não ter sido o mais comum no campo dos serviços públicos, uma vez que a maior parte dos serviços somente pode ser delegada mediante autorização legislativa, entendemos que a edição de lei autorizativa não é necessária, pois, como já dissemos, a delegação de serviços públicos é esteada em razões de conveniência e oportunidade, que somente poderão ser aferidas pelo Poder Executivo, não cabendo ao Poder Legislativo ou ao Poder Judiciário proceder a um juízo de admissibilidade das razões que levaram o Poder Executivo a transferir determinado serviço a terceiros ${ }^{21}$.

As concessões de serviços públicos de saneamento básico, assim como qualquer concessão de serviço público, têm como característica essencial a obrigação de manutenção, durante toda a vigência do respectivo contrato de concessão, do equilíbrio econômico-financeiro da relação jurídica entre a Administração e o concessionário. Isto significa que, a todo tempo da vigência da concessão, a tarifa auferida pelo concessionário deverá ser suficiente para (i) cobrir todos os custos operacionais do concessionário, (ii) repagar os investimentos realizados pelo concessionário para a prestação do serviço.

19 A modalidade de leilão vem sendo utilizada apenas no âmbito federal por força do disposto no inciso VII, do $\S 3^{\circ}$, do artigo $4^{\circ}$, da Lei 9.491 , de 9 de setembro de 1997 (Lei do Programa Nacional de Desestatização), com pouca (ou nenhuma) aplicação para o setor de saneamento básico.

20 Cabe ressaltar que o art. 28, da Lei $8.987 / 95$, permite a criação de penhor sobre os direitos emergentes da concessão para a contratação de financiamentos necessários à consecução do empreendimento.

21 Neste sentido, DI PIETRO, Maria Sylvia Zanella. Parcerias, op. cit., p. 73. 
A manutenção do equilíbrio econômico-financeiro dos contratos de concessão dá-se por meio da revisão e do reajuste dos valores das tarifas. Reajuste é a correção do valor nominal das tarifas realizada periodicamente (normalmente, de forma anual) pelo poder concedente. Já revisão é a correção do valor das tarifas em função dos custos incorridos pelo concessionário na prestação dos serviços.

A revisão pode ser ordinária ou extraordinária. Ordinária é a revisão realizada dentro dos prazos previstos nos respectivos contratos de concessão, enquanto que extraordinária é a revisão realizada a qualquer tempo, desde que comprovada a existência de fato que tenha dado origem a um desequilíbrio da concessão. Tal fato poderá ser algo alheio ao controle das partes (alia extraordinária) ou algo decorrente de ordem do poder concedente (alia ordinária). Nos termos do artigo $9^{\circ}, \S 4^{\circ}$, da Lei $8.987 / 95$, o poder concedente é obrigado a rever o valor das tarifas no caso de alterações unilaterais do contrato de concessão que afetem o equilíbrio econômicofinanceiro.

As concessões de serviços públicos de saneamento básico podem ser extintas em razão: de qualquer dos acontecimentos previstos no artigo 35 da Lei 8.987/95, quais sejam, (i) advento prazo contratual; (ii) caducidade; (iii) encampação; (iv) anulação; (v) rescisão (por mútuo acordo ou ordem judicial a pedido do concessionário) e (v) falência do concessionário.

Em qualquer dos casos de extinção da concessão, o poder concedente é obrigado a indenizar o concessionário pelos investimentos realizados em bens reversíveis (conforme descritos abaixo) não amortizados ou depreciados quando da extinção da concessão, de acordo com o disposto no artigo 36 da Lei 8.987/95.

Por fim, é importante mencionarmos a razão pela qual não incluímos a autorização como forma possível de delegação dos serviços de saneamento básico. Segundo nosso entendimento exposto no item III acima, os serviços de saneamento básico são atividades econômicas titularizadas pelo Poder Público em razão de seu enorme interesse público. Vale dizer, o prestador dos serviços de saneamento básico sempre atuará de forma a atender às necessidades da coletividade, segundo interesses públicos, jamais interesses privados.

Exatamente esta é a razão pela qual a autorização não é instrumento apto a transferir a terceiros a prestação de serviços de saneamento básico, uma vez que a autorização é instrumento prestante apenas para transferir a particulares serviços públicos não titularizados pelo Poder Público. Isto é, a autorização é o instrumento adequado para permitir ao particular exercer, em seu interesse exclusivamente privado, atividades consideradas como serviços públicos. Assim, tendo em vista que os serviços de saneamento básico nunca poderão ser explorados no interesse exclusivamente privado do prestador, entendemos que jamais poderá haver a delegação de serviços de saneamento básico por meio de autorização. ${ }^{22}$

22 Neste sentido, afirma Alexandre Santos de Aragão: "ao se referir à prestação de serviços públicos mediante autorização, a Constituição incluiu entre os serviços públicos atividades não titularizadas pelo Poder Público. Apenas a concessão e a permissão transferem a particulares a execução de serviços públicos de titularidade estatal. As autorizaçōes são instrumentos de ordenação pública de atividades de titularidade privada." In Agências, op. cit. p. 151. 


\section{Remuneração pela Prestação do Serviço de Saneamento Básico}

A distinção da forma de prestação dos serviços de saneamento básico entre prestação direta pelo Estado ou delegada a terceiros descrita acima traz profundas repercussões em matéria da natureza jurídica da remuneração percebida pela prestação dos serviços de saneamento básico, que poderá ter natureza tributária (taxa) ou não (tarifa).

A existência de dois regimes remuneratórios distintos para a prestação do serviço de saneamento básico encontra reflexos extremamente relevantes quanto à disponibilidade, pelo agente prestador, dos recursos auferidos na prestação dos serviços e quanto às regras de fixação do valor da remuneração.

Tais diferenciações constam, fundamentalmente, dos seguintes pontos: a taxa, em virtude de sua natureza tributária, não é disponível pelo prestador do serviço, não podendo ser alienada ou gravada, e somente pode ser criada ou valorada em virtude de lei, ao passo que a tarifa tem natureza de preço público, logo pode ser gravada, mediante prévia anuência do poder concedente (art. 28 da Lei 8.987/95), não depende de lei para ser criada e não tem valor fixado por lei, mas sim por ato administrativo do poder concedente, que deverá fixá-lo com vistas à manutenção do equilíbrio econômico-financeiro da concessão.

A remuneração através de taxa somente pode ser instituída para serviços públicos específicos e divisíveis efetivamente prestados (usufruídos pelos usuários) ou postos à disposição (não necessariamente usufruídos), ou seja, para atividades públicas essenciais determinadas e cujos usuários sejam determináveis ou determina$\operatorname{dos}^{23}$. Por exemplo, o serviço de saneamento básico é um serviço específico e divisível, uma vez que é atividade autônoma cujos usuários são perfeitamente determináveis, podendo ser remunerado por taxa; a contrário senso, o serviço de segurança pública é um serviço específico, mas não é divisível, uma vez que não é possível determinar quem são os usuários de referido serviço, não podendo ser remunerado por taxa.

A instituição de taxa para a remuneração do serviço público de saneamento básico pressupõe a observância de todos os requisitos que regem os tributos, conforme previstos no artigo 150 da Constituição Federal (e.g., necessidade de lei para o estabelecimento do tributo, vedação à sua cobrança no mesmo exercício financeiro de sua instituição, vedação à criação de outro tributo com o mesmo fato gerador, etc.). Adicionalmente, a taxa, por tratar-se de tributo de natureza vinculada, deve sempre corresponder a uma contraprestação estatal, a qual corresponde à própria prestação do serviço remunerado.

23 Segundo Hely Lopes Meirelles, "a especificidade e a divisibilidade ocorrem, em regra, nos serviços de caráter domiciliar, como os de energia elétrica, água, esgotos, telefonia e coleta de lixo, que beneficiam individualmente o usuário e lhe säo prestados na medida de suas necessidades. ensejando a proporcionalidade da remuneração." In Direito Municipal Brasileiro. $6^{\mathbf{a}}$ ed. - 1993. Ed. Malheiros. São Paulo, p. 141. 
Por outro lado, a remuneração através de tarifas poderá ser instituída para serviços públicos específicos e divisíveis efetivamente prestados aos usuários (não pode haver tarifas para serviços públicos meramente postos à disposição dos usuários). Conforme já mencionado, a tarifa tem natureza jurídica de preço público, não estando, portanto, sujeita aos princípios aplicáveis aos tributos. Assim, o valor das tarifas é fixado pela Administração pública e deverá ser alterado sempre que necessário para a manutenção do equilíbrio econômico-financeiro do serviço a ser remunerado.

Preliminarmente, consoante as considerações acima, verifica-se que a remuneração de um serviço público na forma de taxa não é, como regra, aplicável a serviços prestados em regime de concessão ou permissão. Isto ocorre em virtude de a instituição de taxa dificultar ou mesmo inviabilizar na prática a manutenção do equilíbrio econômico-financeiro da relação contratual, uma vez que seu valor não pode ser alterado sempre que houver necessidade em decorrência da aplicação dos princípios aplicáveis a todos os tributos, contrariando o disposto no $\S 2^{\circ}$, do artigo $9^{\circ}$, da Lei $8.987 / 95$.

Portanto, uma primeira distinção entre taxa e tarifa decorre do fato de como regra ser adequada a remuneração através de taxa apenas nas hipóteses em que o Estado presta o serviço diretamente, enquanto que a remuneração através de tarifa pode ser utilizada tanto na hipótese de prestação direta do serviço pelo Estado, quanto na hipótese da prestação do serviço através de concessão ou permissão. ${ }^{24}$

Em excelente assertiva sobre o tema, observa Maria Sylvia Zanella Di Pietro: "a distinção quanto à natureza da imposição, com base no conceito constitucional de taxa, só é cabivel quando o serviço seja prestado diretamente pelo próprio Estado. Contudo, não tem nenhum sentido quando o serviço é prestado por meio de concessão ou permissão, porque a estes institutos é inerente a cobrança de tarifa. Se a Constituição Federal permite a prestação de serviço público por meio de concessão ou permissão, também está permitindo a cobrança de tarifa. Impor a instituição de taxa (sujeita ao principio da legalidade) aos serviços públicos concedidos tornará inviável a utilização da concessão, já que a taxa é inadequada como meio de assegurar ao concessionário o seu direito ao equilíbrio econômico-financeiro." 25

Sendo assim, ao verificarmos que somente a remuneração por meio de tarifa parece ser aplicável aos casos em que haja concessão ou permissão, resta verificar qual a forma adequada para a remuneração de serviços públicos prestados diretamente pela Administração.

Segundo uma primeira análise do inciso II, do artigo 145 , da Constituição Federal e do artigo 175, da Constituição Federal, poder-se-ia entender que há certa discricionariedade da Administração para determinar se a remuneração de determinado serviço público será efetuada através de taxa ou através de tarifa. Contudo, dada a natureza tributária da taxa, não seria conveniente sua instituição para a remuneração de qualquer serviço público. 
Conforme descrito, a taxa não é adequada para a remuneração de qualquer serviço cuja remuneração possa sofrer alterações em decorrência de fatos extraordinários, pois a manutenção do equilibrio econômico-financeiro da remuneração é incompatível com certas garantias constitucionais/princípios tributários, tais como a anterioridade e a legalidade. Desta forma, verifica-se que a adoção de taxa somente seria adequada para a remuneração de serviços públicos que não estejam sujeitos a alterações extraordinárias de custos (como, por exemplo, os serviços judiciários).

No caso de serviços públicos sujeitos a súbitas alterações extraordinárias da equação econômico-financeira, tais como os serviços públicos que demandam a construção e a manutenção de grandes empreendimentos, a remuneração mais adequada será a tarifa, pelas razões acima, como o serviço de saneamento básico, por exemplo.

Neste sentido, afirma Marçal Justen Filho: "a aplicação do regime tributário pressupõe situações em que a mutabilidade das condições da prestação do serviço público seja improvável e imprevisível. Sempre que o fornecimento do serviço público envolver perspectiva de variações de custos ou de inovações derivadas de circunstâncias inerentes à natureza da atividade necessária à satisfação da necessidade coletiva, o regime tributário poderá ser afastado. A natureza da prestação e a impossibilidade de sua submissão ao regime tributário conduzirão à necessidade de adoção da via de tarifa." 26

Assim, diante do exposto, concluímos ser indesejável a remuneração dos serviços de saneamento básico por meio de taxa, sobretudo em casos em que haja delegação do serviço, uma vez que os serviços de saneamento básico são sujeitos a súbitas alterações de custos e a adoção de taxa inviabiliza a imediata recomposição do equilíbrio econômico-financeiro da prestação dos serviços. ${ }^{27}$

\section{Ativos Utilizados na Prestação do Serviço}

Os bens afetos à prestação de serviços públicos concedidos são reversíveis ao Poder Concedente ${ }^{28}$, isto é, são bens que retornarão ao Poder Concedente quando extinta a concessão, gerando direito de indenização ao concessionário no que tange à parcela não amortizada ou depreciada dos investimentos realizados. Tal reversão é devida ao fato de que os bens reversíveis são essenciais à continuidade da prestação dos serviços concedidos, apenas tendo algum interesse ao concessionário para a efetiva prestação dos serviços concedidos. Uma vez finda a concessão, não há razão

26 JUSTEN FILHO, Marçal. Teoria, op cit., p. 349.

27 Cf. DI PIETRO, Maria Sylvia Zanella. Parcerias, op cit., p. 335; JUSTEN FILHO, Marçal. Teoria, op cit., p. 338; e TÁCITO, Caio. Temas, op cit., p. 364. Em sentido contrário, ATALIBÁ, Geraldo. "Abastecimento de Água - Serviço Público Delegado - Taxa". Revista de Direito Administrativo, p. 186/315.

28 Vide art. 18 , inciso $X, e$ art. 23 , inciso $X$, da Lei 8.987/95, e artigo $8^{\circ}$, inciso XI, da Lei 7.835/92 do estado de São Paulo. 
para que tais bens permaneçam com o concessionário. ${ }^{29}$ Por exemplo, que interesse tem um concessionário de serviços de saneamento básico nos ativos utilizados na prestação dos serviços caso a concessão tenha sido extinta? Por óbvio, nenhum, uma vez que os serviços de saneamento básico são atividades titularizadas pelo Poder Público, sendo sua prestação, conforme já mencionamos, apenas acessível por delegação do Poder Público.

Tendo-se em vista o acima exposto, surge a questão da disponibilidade dos bens vinculados à prestação dos serviços pelo concessionário.

Considerando-se que os bens do concessionário vinculados à prestação do serviço têm intrínseca relação com o interesse público e são essenciais à prestação contínua dos serviços, não há como outorgar a estes bens um regime de direito privado. Desta forma, os bens vinculados à prestação de serviços públicos são indisponíveis pelo concessionário, não podendo ser alienados, gravados, locados ou cedidos. Há, inclusive, no art. $7^{\circ}$, inciso VI, da Lei $8.987 / 95$ a expressa classificação de tais ativos como bens públicos, exceto conforme expressa disposição legal em sentido contrário.

Conforme expusemos, os serviços de saneamento básico são serviços nos quais se torna dificultosa a inserção de diversos agentes prestadores para uma mesma região atuando em regime de concorrência, em razão da natureza dos serviços prestados. A única forma viável para a inserção de concorrência seria o estabelecimento da obrigação de livre acesso às redes de suporte dos serviços de saneamento básico, como ocorre, por exemplo, nos setores de energia elétrica e telecomunicações.

Tal obrigação de livre acesso está associada, na maior parte das vezes, a um processo de desverticalização (unbundling) do agente prestador dos serviços, que consiste na obrigatoriedade de separação contábil e/ou empresarial das atividades de prestação dos serviços e administração e gestão das redes de suporte dos serviços. A partir de tal processo de desverticalização, os agentes prestadores são obrigados a prestar atividades passíveis de concorrência conjuntamente com outros agentes e a administrar e gerir as redes de suporte de forma a garantir o acesso de quaisquer terceiros interessados para prestação das atividades sujeitas a concorrência.

No setor de saneamento básico, poder-se-ia cogitar um modelo no qual haja uma separação entre as atividades de adução e distribuição de água e a atividade de transporte de água, inserindo-se competição entre diversos agentes no segmento de adução e distribuição de água. Todavia, tendo em vista as características do setor de saneamento básico, sobretudo à luz das regras de uso dos recursos hídricos (conforme descritas a seguir), não vemos qualquer possibilidade de estruturas deste jaez prosperarem ${ }^{30}$.

29 Cf. MELlO, Celso Antônio Bandeira de. Prestação, op. cit., p. 54 e 55.

30 Este foi, inclusive, o entendimento adotado no Reino Unido quando da privatização das empresas prestadoras de serviços públicos, conforme afirma Simon Cowan: "In water, the implicit assumption at the time of privatization in 1989 was that the whole of the business is naturally monopolistic and that the role of competition would be very marginal." In Competition, op. cit., p. 162. 
Sendo assim, os ativos afetos à prestação dos serviços de saneamento básico não estão sujeitos a obrigações de livre acesso como os ativos afetos à prestação de outros serviços públicos, nem tampouco devem estar. Este entendimento, inclusive, é corroborado pelo que expusemos acerca da impossibilidade de outorga de autorizações para a prestação de serviços de saneamento básico. Isto ocorre, pois a obrigação de livre acesso está diretamente ligada à outorga de autorizações, uma vez que os autorizatários são pessoas privadas que exercem atividades públicas em seu exclusivo interesse privado mediante a utilização de redes de suporte de terceiros (concessionários, via de regra).

\section{Competência Legislativa no Setor de Saneamento Básico}

A Constituição Federal prevê a distribuição de competências legislativas entre os entes da Federação para a disciplina dos serviços de saneamento básico. Desta forma, a Constituição Federal, bem como diversas Constituições estaduais e leis orgânicas contêm disposições acerca da competência legislativa para regulação dos serviços de saneamento básico.

Tal distribuição de competências entre os entes federativos acarreta sérias dificuldades concernentes ao estabelecimento de um marco regulatório sólido para o setor de saneamento básico, tal como ocorre no setor de telecomunicações, por exemplo. O estabelecimento de tal marco regulatório torna-se essencial, e até mesmo imperioso, para se permitir o ingresso de capitais privados na realização dos investimentos necessários no setor de saneamento básico.

No Reino Unido, por exemplo, a privatização do setor de saneamento básico e as demais leis relacionadas aos setores de infra-estrutura, notadamente o Water Industry Act, de 1991, conduziram à criação de um ente regulador único, o Office of Water Services - OFWAT, competente para gerir e regular as concessões e autorizações do setor de saneamento básico, bem como facilitar, e não promover, a competição em referido setor.

No Brasil, contudo, diante da competência municipal (ou estadual) para os serviços de saneamento básico, toma-se bastante dificultosa a edição de regras que estabeleçam um marco regulatório comum a todo o território nacional, como adotado no Reino Unido, uma vez que tal iniciativa pode ser considerada como ofensiva à autonomia dos estados e municípios para disciplinar as matérias de suas competências, ferindo, outrossim, os artigos $1^{\circ}$ e 18 da Constituição Federal.

Diante dessas considerações preliminares, passaremos neste momento a analisar as competências constitucionalmente atribuídas a cada ente federativo para o setor de saneamento básico no Brasil, bem como os impactos de tal distribuição de competências na formação do necessário marco regulatório do setor de saneamento básico brasileiro.

\section{(a) União}

De acordo com o inciso XX, do artigo 21, da Constituição Federal, é competência da União instituir diretrizes para o desenvolvimento urbano, inclusive habi- 
tação, saneamento básico e transportes urbanos. À luz de referido dispositivo constitucional, a Lei 10.257, de 10 de julho de 2001, que instituiu o Estatuto da Cidade, em cumprimento ao disposto nos artigos 182 e 183 da Constituição Federal, determina no inciso IV, do artigo $3^{\circ}$, que é competência da União Federal, no que concerne à política urbana, "instituir diretrizes para o desenvolvimento urbano, inclusive habitação, saneamento básico e transportes urbanos".

Adicionalmente, segundo previsto no inciso XXVII, do artigo 22, da Constituição Federal, é de competência privativa da União estabelecer normas gerais sobre licitação e contratos administrativos. Diante desta competência da União e da competência para o estabelecimento das diretrizes de desenvolvimento urbano, incluindo saneamento básico, verifica-se que a União dispõe de competência para estabelecer normas gerais aplicáveis ao setor, inclusive concernentes a concessões e permissões, facilitando a edição de um marco regulatório comum para o setor de saneamento básico.

Contudo, tendo em vista que a União não poderá instituir um órgão regulador comum, com poder de regulamentar o setor de saneamento básico, verifica-se que, mesmo após a edição de eventual lei federal instituidora das diretrizes do setor de saneamento básico, o marco regulatório do setor de saneamento básico ainda seria por demais fragmentado entre cada uma das unidades competentes para prestar os serviços (Estados, Distrito Federal e Municípios).

Diversos foram os projetos de lei propostos e as leis em âmbito federal para a instituição de referidas diretrizes para o setor de saneamento básico. Todavia, atualmente, não há perspectiva de estabelecimento de um marco regulatório sólido para o setor de saneamento básico, o que, indubitavelmente, dificulta muito a entrada de investimentos privados no setor.

\section{(b) Estados}

Em complementação à competência federal para o estabelecimento das diretrizes gerais relacionadas ao serviço de saneamento básico, as Constituições de diversos Estados determinam caber ao Estado, em conjunto com os Municípios, ou isoladamente, editar normas gerais sobre saneamento básico. Assim, os Estados acabam, em diversas oportunidades, editando normas gerais para a regulamentação do setor de saneamento básico.

Tal competência estadual afigura-se significativamente aceita em nosso ordenamento jurídico, uma vez que a prestação dos serviços públicos de saneamento básico em diversas oportunidades é realizada por companhias estaduais, independentemente da efetiva competência para a prestação de saneamento básico. Vale dizer, mesmo sem haver a constituição de regiões metropolitanas, há um sem-número de Municípios nos quais a prestação dos serviços de saneamento básico é realizada por companhias estaduais, por meio da celebração de convênios, ou até mesmo por meio de concessões.

Por fim, é de se ressaltar que a competência dos Estados com relação ao serviço de saneamento básico torna-se mais evidente nos casos de constituição de regiões metropolitanas, nos termos do $\S 3^{\circ}$, do artigo 25, da Constituição Federal. 
Por fim, a Constituição Federal estabelece em seu artigo 30, inciso I, que compete aos Municípios legislar sobre assuntos de interesse local, dentre os quais se inclui o serviço de saneamento básico. Tendo em vista a competência municipal para a prestação dos serviços de saneamento básico (ressalvada a hipótese de criação de região metropolitana, como se verá), temos mais claramente definida a competência legislativa dos Municípios com relação à matéria de saneamento básico.

Assim, visto ser o Município o competente para prestar os serviços, é, igualmente, o Município o competente para implementar o marco regulatório respectivo para a regulação de referidos serviços. Destarte, verifica-se que, ainda que haja regras federais concernentes às diretrizes para o setor de saneamento básico, o competente para o estabelecimento de um marco regulatório será o Município.

Tal assertiva pode dificultar o estabelecimento de um marco regulatório sólido e propício para o setor de saneamento básico, uma vez que os riscos políticos em âmbito municipal são consideravelmente maiores, em razão da maior volatilidade das normas municipais. Um dos principais objetivos (senão o principal) da regulação setorial independente é elidir, ou ao máximo mitigar, a interferência política na prestação dos serviços regulados, mediante a separação entre funções políticas e a prestação dos serviços públicos, a fim de retirar do campo da prestação dos serviços públicos a volatilidade das decisões políticas ${ }^{31}$. Todavia, o que se verifica na enorme maioria dos Municípios brasileiros é a considerável dificuldade em se dissociar funções políticas de funções de administração, o que pode muito dificultar, ou mesmo inviabilizar, o estabelecimento de um marco regulatório efetivo para o setor de saneamento básico.

Destarte, o que acaba por se verificar é a maior facilidade dos grandes centros desenvolvidos, ou em acelerado ritmo de desenvolvimento (quase sempre em regiões metropolitanas), de estabelecer ambientes regulatórios mais sólidos e confiáveis, proporcionando maiores investimentos privados. Por outro lado, os menores Municípios, com maiores necessidades de investimentos em saneamento básico, por não conseguirem muitas vezes propiciar um marco regulatório sólido e confiável, acabam não recebendo os investimentos necessários. Tal situação é absolutamente condenável à luz do Princípio da Universalidade dos Serviços Públicos.

A participação privada no setor de saneamento básico não pode, de forma alguma, implicar a desregulação de referido setor. Muitíssimo pelo contrário. $O$ sucesso da abertura do setor de saneamento básico à iniciativa privada está direta-

31 A este respeito, Floriano de Azevedo Marques Neto afirma que: "Neste cenário, a vontade política (entendida como a orientaçāo do governante) se punha muito mais eficaz (demandando menor necessidade de mediação para sua concretização). Porém, a atividade econômica, é fato, acabava por padecer de uma enorme instabilidade, pois as decisões políticas são necessariamente cambiantes (fruto da natural necessidade de acomodação dos interesses politicos e das premências da alternativa de poder) e buscam responder às demandas mais imediatas." In Agências Reguladoras - Instrumentos de fortalecimento do estado. Texto publicado pela Associação Brasileira das Agências de Regulação - ABAR. São Paulo, maio de 2003, p. 10. 
mente associado à boa regulação setorial. Diante das competências legislativas aqui descritas, verifica-se ser fundamental uma interface entre cada um dos entes federativos para a construção de um marco regulatório para o setor de saneamento básico, conforme a competência legislativa constitucionalmente atribuída a cada ente federativo. ${ }^{32}$

\section{Competência para Prestar, Regular e Outorgar Serviços de Saneamento} Básico

A competência para a prestação dos serviços de saneamento básico e para a outorga de concessões para a prestação de referidos serviços por meio de delegação dependerá da existência ou não de interesse metropolitano em tal prestação.

A Constituição Federal, em seu artigo 30, inciso V, dispõe que:

\section{"Art. 30. Compete aos Municipios: \\ (...) \\ $V$ - organizar e prestar, diretamente ou sob regime de concessão ou permissão, os serviços públicos de interesse local, incluído o de transporte coletivo, que tem caráter essencial.(...)" (grifos nossos)}

Diante do sobredito artigo, entende-se que a competência para prestar os serviços de saneamento básico no Brasil é municipal, uma vez que os serviços de saneamento básico são considerados serviços públicos de interesse local, uma vez que o utente final dos serviços é o munícipe. Nada impede, contudo, que o município transfira a outro ente federativo, mediante convênio administrativo, a competência para prestar os serviços de saneamento básico, em consonância com o entendimento exposto acima.

Todavia, essa competência é radicalmente alterada quando se verifica a formação de uma região metropolitana ${ }^{33}$, uma vez que o interesse local dos serviços passa a não se limitar mais a apenas um município, mas sim a uma aglomeração de diversos municípios limítrofes, onde, muitas vezes, a fonte dos recursos hídricos deixa de ser exclusivamente municipal. Assim, a competência para a prestação dos serviços de saneamento básico desloca-se do município para o Estado no caso de formação de região metropolitana, nos termos do $\S 3^{\circ}$, do artigo 25, da Constituição Federal.

32 Ao tratar da questão da regulação dos serviços de saneamento básico, Floriano de Azevedo Marques Neto muito bem pondera que: "A definição dos marcos regulatórios para o setor não prescinde da adoção de mecanismos de interlocução entre as três esferas da federação, em especial com os Municípios." In "Aspectos Regulatórios em um Novo Modelo para o Setor de Saneamento Básico no Brasil”. Revista de Direito Administrativo 224/89.

33 Segundo previsto no $\S 2^{\circ}$, do artigo 25 , da Constituição Federal, as regiões metropolitanas são constituídas por agrupamentos de municípios limítrofes e podem ser instituídas pelos Estados, por meio de lei complementar, com vistas à integração da organização, do planejamento e da execução de funçōes públicas de interesse comum. 
A este respeito, o mestre Caio Tácito ensina que: "De duas formas poderá se deslocar do Município para o Estado (representado por órgãos ou entidades de sua administração) a efetividade da prestação de serviços de saneamento básico, ou, pela via coercitiva de integração, a que se refere a previsão do art. $25, \S 3^{\circ} \mathrm{da}$ Constituição, pela via da lei complementar, ou, em menor grau de integração, mediante acordo, consubstanciado em convênio administrativo quando não venha a ser criada Região Metropolitana." 34

Com relação a esta questão, é importante mencionar a recente Lei $n^{0} 13.670$, de 25 de novembro de 2003, do Município de São Paulo, que teve por objeto estabelecer o marco regulatório do setor de saneamento básico no Município de São Paulo, incluindo a criação de um órgão regulador independente, a Autoridade Reguladora dos Serviços de Água e Esgotamento Sanitário de São Paulo. Inobstante o consolidado interesse no sentido de deslocamento da competência para os Estados nos casos de criação de regiões metropolitanas, tal lei municipal expressamente determina ser do Município de São Paulo a competência para a prestação e regulação dos serviços de saneamento básico (parágrafo único, do artigo $9^{\circ}$ ).

Em que pese referida lei criar um marco regulatório sólido para o setor de saneamento básico, entendemos ser inconstitucional a avocação para o Município de São Paulo da competência para prestar e regular os serviços de saneamento básico, em razão da existência de região metropolitana (afronta ao $\S 3^{\circ}$, do artigo 25 . da Constituição Federal, e ao artigo 153, da Constituição do Estado de São Paulo).

A este respeito, é importante mencionar que tramita perante o Tribunal de Justiça de São Paulo uma Ação Direta de Inconstitucionalidade proposta pelo governador do Estado de São Paulo questionando a constitucionalidade da lei paulistana (ADIN 109.600/0). Até este momento, referida ação não foi julgada. Todavia, os efeitos de determinados dispositivos da lei paulistana (incluindo a avocação de competência para o Município de São Paulo) encontram-se suspensos por força de liminar concedida pelo Desembargador Presidente do Tribunal de Justiça de São Paulo. ${ }^{35}$

\section{Utilização e Propriedade das Fontes dos Recursos Hídricos}

Nos termos dos artigos 20, inciso III, e 26, inciso I, da Constituição Federal, respectivamente, pertencem à União as águas que banhem mais de um Estado e pertencem aos Estados as águas localizadas exclusivamente dentro de seus respectivos territórios. Na mesma linha, dispõe o artigo 29, do Código das Águas (Decreto $\mathrm{n}^{\circ} 24.643$, de 10 de julho de 1934), que pertencem à União as águas que banhem

34 Cf. TÁCITO, Caio. Estudos e Pareceres, op. cit., p. 376.

35 Após o provimento liminar. o Município de São Paulo interpôs Agravo Regimental (Processo $\mathrm{n}^{\circ}$ 109.600.0/5-01), com vistas à revogação da medida liminar concedida. Tal agravo, entretanto, teve seu provimento negado, por decisão unânime, em Sessão Plenária realizada em 10 de março de 2004. 
mais de um Estado, aos Estados as águas que banhem mais de um município e aos Municípios as águas localizadas exclusivamente dentro de seus territórios.

Desta forma, verifica-se que o ente federativo competente para prestar os serviços de saneamento básico (Municípios, conforme descrito no item VIII acima), via de regra, não dispõe dos recursos hídricos necessários à prestação de tais serviços, uma vez as fontes de recursos pertencerem mais comumente à União ou aos Estados federados.

A solução para esta questão dependerá, portanto, de mecanismos jurídicos que possibilitem aos municípios a utilização de recursos que compõem o patrimônio de outros entes federativos. No caso de águas pertencentes à União, a utilização dos recursos hídricos dá-se por meio de autorizações do direito de uso de recursos hídricos outorgadas pela Agếncia Nacional de Águas, ${ }^{36}$ nos termos do inciso IV, do artigo $4^{\circ}$, da Lei 9.984 , de 17 de julho de 2000 . No caso de águas estaduais, a regulamentação do direito de uso dependerá da legislação de cada Estado. Comumente, a forma jurídica adotada para disciplinar o uso, por municípios, de recursos hídricos pertencentes aos Estados, é a de um convênio administrativo celebrado entre os respectivos Estado e município.

\section{Parcerias Público-privado no Setor de Saneamento Básico}

Atualmente, pretende-se implementar no Brasil as parceiras público-privado. As parcerias público-privado são formas de associação entre a Administração Pública e os particulares para a consecução de empreendimentos e atividades de interesse público, mediante a repartição dos riscos decorrentes de tais empreendimentos ou atividades entre a Administração Pública e os particulares contratados.

A estrutura das parcerias público-privado, surgida no Reino Unido na primeira metade da década de 90 , é amplamente utilizada em diversos países europeus para a realização de empreendimentos de interesse público, tanto aqueles empreendimentos relacionados com a prestação de serviços públicos (rodovias, hospitais, transportes, etc.), quanto aqueles empreendimentos relacionados a obrigações administrativas do Estado (presídios, prédios públicos, etc.).

Conforme mencionado, os serviços de saneamento básico podem ser desenvolvidos de duas formas distintas, quais sejam: a execução direta pela Administração e a delegação, por meio de concessões ou permissões, a particulares.

No sistema das parcerias público-privado, conforme mencionado, a Administração associa-se a um particular com a finalidade de realizar um empreendimento de interesse público ou prestar um serviço público, sendo ou não necessária a construção de uma obra pública, configurando-se a estrutura como um modelo

36 A Lei Federal n 9.984/00, instituiu a Agência Nacional de Águas - ANA, agência federal vinculada ao Ministério do Meio Ambiente, cujo objetivo consiste em implementar a Política Nacional de Recursos Hídricos, sendo parte integrante do Sistema Nacional de Gerenciamento dos Recursos Hidricos, previsto na Lei Federal $n^{\circ}$ 9.433/97. 
híbrido entre a prestação direta pelo Poder Público e a delegação por meio de concessão ou permissão.

Tal afirmação decorre do fato de que na estrutura das parcerias público-privado o Poder Público associa-se com o particular com a finalidade de realizar determinado empreendimento de interesse público sendo o particular remunerado mediante a repartição das receitas auferidas pelo Poder Público na prestação do serviço ou exploração do empreendimento ou com recursos orçamentários.

A distinção essencial entre as parcerias público-privado e as terceirizações realizadas nos termos da Lei 8.666, de 21 de junho de 1993, consta exatamente da questão da remuneração do parceiro privado e da alocação de riscos. Enquanto nas terceirizações os pagamentos são devidos na medida em que marcos contratuais são atingidos, nas parcerias público-privado os pagamentos são realizados em prazos mais longos, de acordo com a performance do particular. A quitação dos pagamentos devidos nas parcerias público-privado não é coincidente com a conclusão do empreendimento, como ocorre no das terceirizações. Assim, os riscos decorrentes do empreendimento são repartidos entre Administração e parceiro privado, ao passo que nas terceirizações o risco é integralmente assumido pela Administração.

De outra forma, as parcerias público-privado são distintas das concessões e permissões de serviços públicos igualmente em razão da remuneração auferida pelo particular e pela alocação de riscos entre particular e Administração. Na concessão e na permissão de serviços públicos, o particular remunera-se por meio das tarifas pagas diretamente pelos usuários do respectivo serviço público ou da respectiva obra pública, enquanto que nas parcerias público-privado o particular remunera-se por meio de repasses de tarifa realizados pelo Poder Público (que recebe diretamente as tarifas pagas pelos usuários) ou por meio de recursos orçamentários. Por consequiência, verifica-se que nas concessões e permissões os riscos (de solvência dos usuários, por exemplo) são assumidos pelo particular, ao passo que nas parcerias, conforme já afirmado, os riscos são repartidos entre Administração e particulares,

As parcerias público-privado aparecem como uma excelente alternativa para o aumento de investimentos no setor de saneamento básico, uma vez que permite a estruturação de formas bastante rentáveis de consecução de empreendimentos públicos. Isto ainda pode ser comprovado, por exemplo, a partir da análise da experiência vivida por outros países, como Portugal, onde a utilização das parcerias público-privado permitiu uma considerável expansão da universalização dos serviços de saneamento básico.

Contudo, ainda que os instrumentos reguladores das parcerias público-privado sejam sólidos, deve-se sempre ter em mente que nenhum investimento será possível sem a edição de um marco regulatório igualmente sólido para o setor de saneamento básico, de acordo com as premissas expostas acima.

\section{Conclusão}

Procuramos, ao longo deste trabalho, expor os pontos mais controvertidos e relevantes concernentes aos serviços de saneamento básico no Brasil. A partir da 
análise da experiência de outros países e diante de tudo o que restou exposto, concluímos que o efetivo ingresso de capitais privados no setor de saneamento básico depende, essencialmente, do estabelecimento de um marco regulatório sólido e eficaz, bem como da definição de questões que até hoje restam extremamente controvertidas, como a definição de taxa ou tarifa para a remuneração e a definição da competência para prestação dos serviços entre Estados e Municípios. Apenas quando da resolução definitiva de tais questões será possível a efetiva abertura do setor à iniciativa privada. Caso contrário, tentativas malfadadas até hoje ocorridas deverão repetir-se.

\section{Bibliografia}

AMARAL, Diogo Freitas do / TORGAL, Lino. Estudos sobre Concessões e Outros Actos da Administração. $1^{a}$ ed. - 2002. Ed. Almedina. Coimbra.

ARAGÃo, Alexandre Santos de. Agências Reguladoras e a Evolução do Direito Administrativo Econômico. $1^{\text {a }}$ ed. - 2002. Ed. Forense. Rio de Janeiro. Serviços Públicos e Concorrência. Revista de Direito Administrativo, 233/337.

ATALIBA, Geraldo. Abastecimento de Água - Serviço Público Delegado - Taxa. Revista de Direito Administrativo 186/315 e ss.

AZEVEDO NETO, Floriano Marques. Agências Reguladoras - Instrumentos de fortalecimento do estado. Texto publicado pela Associação Brasileira das Agências de Regulação - ABAR. São Paulo, maio de 2003.

Aspectos Regulatórios em um Novo Modelo para o Setor de Saneamento Básico no Brasil. Revista de Direito Administrativo, 224/79 e ss.

COWAN, Simon, Competition in Regulated Industries, $1^{\mathrm{a}}$ ed. -1998 . Oxford University Press. Oxford.

DI PIETRO, Maria Sylvia Zanella. Parcerias na Administração Pública. $4^{\mathrm{a}}$ ed. 2002. Ed. Atlas. São Paulo.

JUSTEN FILHO, Marçal. Teoria Geral da Concessão de Serviços Públicos. $1^{\mathrm{a}}$ Edição - 2003. Ed. Dialética. São Paulo.

MEIRELLES, Hely Lopes. Direito Municipal Brasileiro. 6 ${ }^{\mathrm{a}}$ ed. - 1993. Ed. Malheiros. São Paulo.

MELLO, Celso Antônio Bandeira de. Curso de Direito Administrativo. $13^{\mathrm{a}}$ ed. 2001. Ed. Malheiros. São Paulo.

Prestação de Serviços Públicos e Administração Indireta. $2^{\mathrm{a}}$ ed. - 1983. Ed. Revista dos Tribunais. São Paulo.

TÁCITO, Caio. A Configuração Jurídica do Serviço Público. Revista de Direito Administrativo 233/373-376.

Temas de Direito Público (Estudos e pareceres). $1^{\mathrm{a}}$ ed. - 2002. Ed. Renovar. Rio de Janeiro. 


\section{Temas de Direito Público}

Caio Tácito

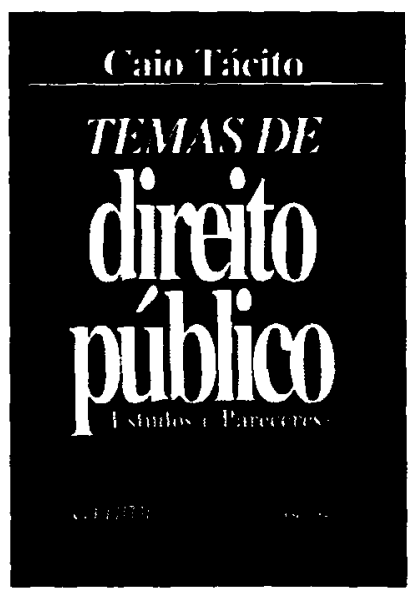

Na presente obra estão ordenados trabalhos doutrinários de várias épocas, frutos de vinte e cinco anos de magistério e de consultoria jurídica. Não obstante a diversidade no tempo, permitem imprimir à coletânea o aspecto sistemático de um manual. São, em maior parte, recentes, mas todos guardam plena atualidade, espelhando a permanência de princípios e conceitos científicos.

Ref. 0154

Form. 16x23
Encadernado

2 vols.
2.100 págs.

1997

\section{Teoria dos Direitos Fundamentais}

Org. Ricardo Lobo Torres

Esta coletânea de artigos e ensaios tem por objeto o estudo da fundamentação, eficácia, extensão e interpretação dos direitos básicos, tanto no plano constitucional como no internacional. Os direitos fundamentais se confundem com os direitos humanos. A retomada da reflexão sobre os direitos fundamentais começa a acontecer nas Faculdades de Direito, que nas últimas décadas a haviam abandonado, seja pela pesada crosta de positivismo que predominou no ensino jurídico, seja pela afasia no discurso da liberdade condicionada por motivos políticos.

Ref. 0219

Brochura

Form. 14x21 1999

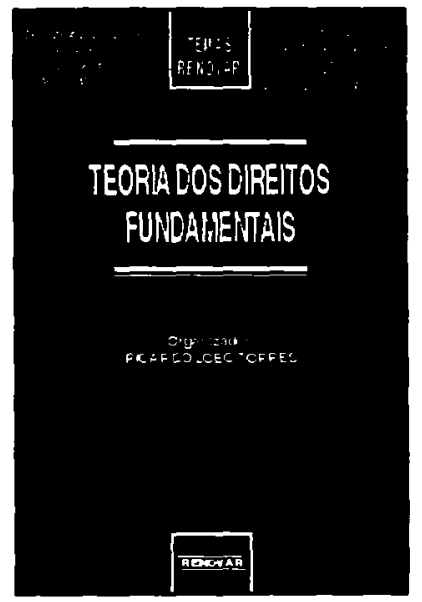

